\title{
The Impact of Adopting Web 2.0-Based E-Book on Student Learning Skills
}

\author{
Hatim Ibrahim ${ }^{1^{*}}$, Abdullah Saad H Alqahtani ${ }^{2}$ \\ ${ }^{1}$ Educational Technology Department, Faculty of Specific Education, South Valley University, EGYPT \\ 2 Educational Technology Department, College of Education, Imam Abdulrahman Bin Faisal University, SAUDI ARABIA
}

Received 8 October 2017 • Revised 27 February 2018 - Accepted 5 April 2018

\begin{abstract}
The present study aims to design an e-book based on Web 2.0 applications: Wiki editors, Video casting and Rich Site Summary (RSS). It identifies the criteria for the proposed e-book and its impact on developing the skills of designing and utilizing Cloud Data. The sample consisted of (60) students divided into two groups: the control group (25) and the experimental group (25), and (10) students for pilot study. The results identified the principles for designing an e-book based on Web 2.0 applications. There were statistically significant differences at the level of $(0.05)$ between the mean scores of the participants in the pre- and post-test for the skill performance observation card. There were statistically significant differences at $(0.05)$ between the mean scores of the participants in the pre- and post-cognitive skills test. The results also indicated that the e-book based on Web 2.0 applications effectively achieved more than (1.2\%) gain ratio.
\end{abstract}

Keywords: e-learning, web 2.0 applications, e-book, cloud data warehouse

\section{INTRODUCTION}

In the light of the significant developments in the e-learning field, it has become a necessity to furnish schools with techniques and device required for applying the e-school system. As such, developing electronic educational sources such as e-books, e-laboratories and e-library required in various educational fields. Mazen (2009) states that e-learning is also considered an adequate and modern educational method to share the required information in the shortest time possible with less efforts and optimum benefit. According to Al-Dahsh (2007), the goals of e-learning have to be achieved throughout the educational process. Such goals include the provision of a rich educational environment that serves the educational process as well as modeling of education in a standard form such as the optimum utilization of the multimedia techniques and the model question banks. This is in addition to mainstreaming technological innovations in all educational institutions and the preparation of a generation of teachers and students capable of dealing with such technological innovations.

\section{THEORETICAL FRAMEWORK}

The idea of e-book introduced in the early 1990s by Bob Stein, who compared reading through the computer screen and reading from a paper book, concluding that reading from an electronic device is better than reading from a paper book. E-Book is a cognitive tool that contains interactive learning modes based on the senses of hearing and seeing and uploaded on a site to be available to the largest number of learners. It allows the instructors and learners to store their work and enhance it with multimedia, besides the possibility of updating the content (Abu Shawish, 2013).

The e-content is managed through the Learning Content Management System (LCMS) known as MOODLE after being redeveloped to suit the nature of the educational system in general (Shimi, 2013). It helps provide flexible curriculum in line with the latest curriculum at the international level, it is a method of teaching technology and self-education, it contributes to improving the quality of teaching and learning through providing pictures, movies

(C) 2018 by the authors; licensee Modestum Ltd., UK. This article is an open access article distributed under the terms and conditions of the Creative Commons Attribution License (http://creativecommons.org/licenses/by/4.0/). $\square$ hatimhaeky@yahoo.com (*Correspondence) $\square$ asalqahtani@iau.edu.sa 


\section{Contribution of this paper to the literature}

- E-learning has become a necessity, due to the recent developments of communication and information technology. Educational institutions are concerned with introducing new types of scientific content in the form of independent learning objects, and also in employing the latest specialized software in the production and development of such content, while taking global standards into consideration.

- The present study is based on producing the proposed e-book through innovative tools, techniques and web 2.0 tools.

- There is a scarcity in the studies that tackled the severe deficiency in the skills of utilizing Cloud Data Warehouse among university students in particular.

and audio recordings and it is an interesting way to attract student by replacing the traditional approaches of memorization and indoctrination. Moreover, e-book characterized by its storage capacity and rapid retrieval of information, besides mainstreaming the use of computers in the information centers and the private sector as well as on-line retrieval of information. It also provides full interaction with students through images and animation in order to increase their ability to understand and analyze as well as the provision of simulation-based software similar to experience without exposing students to the danger of direct communication with such experience.

The forms of e-book vary in terms of design, content and treatment of the educational material, such as text ebooks, picture text e-books, and multimedia e-books. These types include a set of digital systems and tools, including digital images of scanned book pages, Compressed HTML Help (CHM) system, PDF, TXT and RTF system. It can be designed by Notepad, WordPad in Microsoft Windows and HTML. DjVu, on the other hand, opens by a Program added to the Internet browser. It is originally a type of files specified to the collection of scanned books images.

\section{Criteria of Designing E-Books}

It is necessary to refer to a set of criteria related to the effective use of the above-mentioned tools in the design of the proposed e-book. These criteria include technical criteria of designing e-books, color, and image as well as the criteria of using of images and forms. This is in addition to the technical criteria of animations referred to by several studies, such as Batoush (2002), El-Khoury (2000), Sadiq (2001) and Ismail (2009). Such criteria include: Ease of access to and exit from e-books, ease of transition to the final test without passing through all units, the screen should contain tools that help have an easy control of the presentation of information and the display of the content alternatives, specified timing to display the question on the screen and balance within the screen design. In addition, focus must be on graphics, rather than text and more than one screen design for the e-book should be utilized while maintaining consistency between the screens. For the window, utilizing more than one window on the same page contributes to the good use of the page space, while the size of window displaying videos or animation must be adjusted to the size of the screen so as to achieve image clarity and lower storage.

The present study included several components utilized in the design of e-books. Within this context, Azmi (2008) and Al-Garf (2008) pointed out that e-courses consist of a set of media of different shapes such as graphics, texts, exercises, tests and records to save scores, and they may also contain animations, simulations, sounds and links connected with other sites. The most important components include: Course homepage, course tools, information about faculty members who use the course, announcements, discussion board, chatroom, information about the course, course content, homework drop box, tests and evaluation, grade book, course statistics, e-mail center, shared files, memo page, video conferencing, and control panel.

\section{E-learning, Web 2.0 and Cloud Data Warehouses}

The emergence of the Internet as a major information phenomenon is a reality that imposed itself on various scientific and social fields, leading to a change in their characteristics, tools, interactions and effects. Education is no exception. The Internet has passed through several generations where the first phase called Web 1.0, followed by the second phase, called Web 2.0. It is distinguished by interactivity, since its applications enable visitors and users to participate and create content. The Web 2.0 is a term that describes the second generation of the evolution of Internet technologies that allow individuals to change or influence the content of the Web. The social networking is designed for multiple purposes such as facilitating relationships; it is a learning environment based on the Web 2.0 tools (Gardner, 2008). They are used in web-based learning methodologies to create rich and flexible learning environments and promote active learning among students. Teaching and learning approaches are diverse and thus provide an access to Web 2.0 tools that provide new models for the design of education. Such approaches will prepare the best citizens, employees and learners for a knowledge-based society since the idea of Web 2.0 is based on rendering the Internet a platform where everyone can write, interact, and participate. 
Within this framework, Livingstone and Bulger (2015) identified Web 2.0 as a generation of Internet technology, which came out due to cumulative changes in terms of how to use and design the Internet. It does not mean technical update of software or hardware, but it changes the way of using the Internet. It is considered widespread social networks, which include a range of applications and participatory tools as well as services that provide learners with the opportunity to create e-learning materials, besides the personal learning environments which reflect the new version of the Web 2.0. It is concluded that Web 2.0 is a system works in an integrated manner with Web 1.0 and a modern technology used in designing interactive web pages. It can be defined as the technical development that spread around the world through the use of the Internet, advanced programs and integrated systems. It is characterized by ease of mobility and speed of implementation of orders; it also provides users with the opportunity of interaction and positive communication. Tim O'Rally, the first user of the term Web 2.0, indicates four key points, namely: Interaction, Social communication, Collective Contribution to Content Production and Immediate participation (Mabrouk, 2011).

The components of Web 2.0 includes social media, classification of Web 2.0 tools, comments and posts, sharing content and web pages. In the current study, Web 2.0 utilized as a major component in designing the material of experimental processing of the e-book because of its special features. Web 2.0 deals with the web as an integrated development platform away from any other technical elements and the site takes advantage of the network resources and characteristics, the same way the developer benefits from the system orders while programming. Web 2.0 characterized by creativity, intelligence and collective intelligence in utilizing, networking and development, which aims to promote and publish the content among members. In Web 2.0 sites, data, i.e. digital content, is the most important element, including method of content display, quality and processing by content production, recording, publishing, collecting or organization. Livingstone and Bulger (2015) indicated to the importance of using Web 2.0, especially in the field of education. Web 2.0 forms the basis of social networking systems that improve student results. It enhances student participation in college, academic performance, and interaction with faculty and management. It stimulates opportunities for students and faculty towards positive and creative learning process. It contributes to the exchange of experiences among educators and helps to keep the impact of learning. Student role developed to serve as the producer of the substantive content and evaluate themselves.

Furthermore, cloud computing is a Web 2.0 applications through which a large section of personal computer use converted to the cloud. The term of cloud computing was first utilized in the late 1960s, inspired by the cloud code, which was often utilized to represent the Internet in maps and graphs. In the educational process, cloud computing enables the user to access his files and applications without installing the software on his/ her device. It saves a lot of money required to buy the software and reduces cost through reducing the number of the required hardware and employees of hardware and software maintenance. The current infrastructure of cloud computing includes data centers capable of providing service to customers all over the world. By utilizing cloud computing service, learners can conduct online tests, easy access to tests, exercises, projects and feedback, easy communication between students and learners, utilize applications without download, access to stored files from any computer through the Internet and access to all programs at any time and from any place.

\section{Utilizing Digital Data Warehouses}

With the serious developments in the field of education technology, digital revolution emerged and digital technology became the dominant element in various fields general and in education in particular. Digital technology characterized by proving a large and varied digital sources, many of which are related to the educational process, including: the Internet, e-mail, electronic journals, digital libraries, chat programs, e-books, etc. which solved many educational problems such as lack of research data, large number of students, shortage of teachers, weak communication methods between the teacher and students, and the difficulty of retaining and copying the scientific material easily and quickly with the possibility of converting it to various forms, while saving time, effort and cost of learning assignments and activities for student and teacher. Learning through digital sources is significant, because of developing self-learning skills by searching printed and non-printed educational resources, acquiring some skills such as observation accuracy and results analysis, developing innovative thinking skills, developing scientific thinking and problem solving skills and develop the skills to deal with multiple means of communication.

\section{Literature Review}

Gewertz (2012) explains that e-learning and the internet are deemed a fertile land for the growth of a collaborative learning environment. They provide social aspects of collaborative learning through some available collaborative tools. It is based on the exchange of information among a group of learners who frame discussions 
and reorganize materials or concepts to build new relations among each other through receiving feedbacks from their colleagues in the group.

Several studies, including Milman (2009), Al-Naeimi (2001), Al-Far and Shahin (2001), Al-Hadi (2001), Reynolds (2002), Artman (2003) and Ateya (2003) emphasized that e-learning environment is effective in educational technology owing to its numerous advantages: motivating students, helping them understand and attracting their attention, developing their metacognitive skills, achieving effective active learning, and developing tendencies towards technological innovations. Among the studies that asserted the impact of e-book on the cognitive and skill performance were Al-Hoseiny (2005) who ascertained the effectiveness of e-book in the cognitive performance in the Computer Maintenance Course and Mahmoud (2007) who emphasized the effectiveness of e-book in developing academic achievement and self-leaning skills among female students teachers in the Educational Technology Course and their impression of the Course.

Shiratuddin, Gibb, and Hassan (2005) referred to the impact of e-book on student performance through increasing their academic achievement and the influence of electronic learning environments. Rowhani (2005) stated that visual components of the e-book contributed to increasing the quantity of educational content as well as the various activities that address all the senses of learners. Ismail (2013) further laid an emphasis on the significance of electronic usage in developing the cognitive aspect relating to dealing with computers and the motivation of achievement among the third-year preparatory students.

Although e-book has proved to be effective, it has not been tested with the utilization of Web 2.0 applications. According to Downes (2006), Web 2.0 for e-learning is launched in late 2005 by the Institute for Information Technology's E-learning Research Group affiliated to the National Research Council of Canada Moncton, New Brunswick, which developed globally known standards in educational units, blogs and wiki. Web 2.0 for e-learning defined as small units of information that are flexibly linked together, while utilizing separate but complementary tools via the web. They further depend on wiki, blogs and other social internet applications that support the formation of web-based learning communities. Web 2.0 techniques are based on a number of main interactive and communicative tools, the most important of which are Wikis, Blogs, Social Bookmark, and Social Networks. Virtual collaborative learning is also considered one of the most modern learning and training techniques and it is called E-Learning 2.0, which means learning through social networks that allow content editing and updating by inserting a comment, or uploading a file. Thus, everyone is allowed to read, write and share, according to Hassan (2008).

Ramal (2009) states that the database techniques significantly developed over ages from Hierarchique through Relationally to Oriented Object. On the other hand, databases changed from being storage and search databases to information warehouses that help the process of decision making. Thus, the existence of new information systems that deal with such data in terms of storage and restoration has become necessary to enhance planning and future vision.

Data-Warehouse is a database that includes an immense amount of data to support the decision-making process inside an institution. This type of database is characterized by the Star Schema which complies with the user's needed indicators and includes historic data derived and extracted from the continuously updated database used in the applications. Cloud Data Warehouse is subject oriented, integrated and nonvolatile. Databases are considered one of the modern techniques for storing and restoring data; the significance of such technique is expected to increase in the future to handle the organization of the great quantity of information relating to major projects. This refers to the existence of the Database Management DBMS (Systems), which is a set of ready applications that carry out all functions required from the Database (Sorour, 2003).

\section{Statement of the Problem}

The skills of utilizing the Cloud Data Warehouse are weak among the students of the Computer Courses, in general, and the Database Courses, in particular. The problem was emphasized through the traditional teaching method, lack of interaction between instructors and students and a lack of material resources in educational institutions. This is in addition to the lack of sufficient Arabic books in the field, the short time dedicated to Computer courses, only one lecture per week, and student inability to master the skills of designing warehouses data. Through Exploratory Study, a cognitive test applied and an observation card on a group of 60 students enrolled in the Computer Applications Course to measure the cognitive aspect and skilled performance of the Cloud Data Warehouse-related skills. The results showed that: a) Computer knowledge and skills are weak by 70\%; b) The Cloud Data Warehouse-related skills are weak by $90 \%$; c) Students are unable to design the Cloud Data Warehouse-related skills in the laboratory due to time limitations and the lack of material resources.

On the other, there is a need to utilize Web 2.0 based e-books in developing the skills of designing and utilizing Cloud Data Warehouse, so that the role of learners can be both receiver and producer of information. Accordingly, the educational course will be more flexible and influential through discussions and new methods of delivering information such as Blogs, Wiki and social media, which provide learners with several skills and enable them to 
develop themselves through ongoing communications among various leaners. Such new methods will further result in creativity and innovation in developing the educational content.

In light of the previous studies, surveys and the experience of the researchers, it has been proved that there is a lack of the skills of designing and utilizing Cloud Data Warehouse among the students of University of Imam Abdul Rahman bin Faisal due to the adoption of traditional teaching methods. Therefore, taking into consideration the significance of the Web 2.0 based e-book, the present study attempts to design a Web 2.0 based e-book to develop the skills of designing and utilizing Cloud Data Warehouse among the students of University of Imam Abdul Rahman bin Faisal and to identify the impact of such proposed e-book in developing the cognitive and performance aspects of such skills.

\section{Questions}

This problem can be solved through answering the following questions:

1. What are the cognitive skills necessary for designing and using Cloud Data Warehouse needed to be developed among the students of University of Imam Abdul Rahman bin Faisal?

2. What is the proposed vision for Web 2.0-based e-book for developing the skills of designing and utilizing Cloud Data Warehouse among the students of University of Imam Abdul Rahman bin Faisal?

3. What is the impact of Web 2.0-Based E-Book on the cognitive performance of the Skills of designing and utilizing Cloud Data Warehouse among the students of the college?

4. What is the impact of Web 2.0-Based E-Book on the skilled performance of the Skills of designing and utilizing Cloud Data Warehouse among the students of the college?

\section{Objectives}

The present study aims to:

1. Develop a list of the basic skills necessary for designing and utilizing Cloud Data Warehouse needed to be developed among the students of University of Imam Abdul Rahman bin Feisal.

2. Design a Web 2.0-based e-book to develop skills necessary for designing and utilizing databases and identify the contents and objectives of such book.

3. Study the impact of Web 2.0-based e-book on developing the cognitive and skilled aspects of the skills necessary for designing and utilizing Cloud Data Warehouse among students of University of Imam Abdul Rahman bin Faisal.

4. Direct the attention of officials of institutions of higher education to the need to use electronic books in the educational process in order to develop and improve teaching methods using modern technology.

\section{Hypotheses}

1. There was a significant difference between the mean scores of student in the cognitive test of the experimental and control groups, in favor of the experimental group, due to the impact of e-book based on Web 2.0 on developing the skills of utilizing data warehouse in post-measurement.

2. There was a significant difference between the mean scores of students in the skill performance observation card of the experimental and control groups, in favor of the experimental group, due to the impact of e-book based on Web 2.0 on developing the performative skills of utilizing data warehouse in post measurement.

\section{METHODOLOGY}

The quasi-experimental approach utilized to verify the study hypotheses and measure the impact of e-book proposed to develop the skills necessary to design and utilize data warehouse through identifying the causality between the independent variable and the dependent one. The independent variable is a web 2.0-based e-book, while the dependent variables include the cognitive aspect of designing and utilizing Data Warehouse and the performance aspect of designing and utilizing Data Warehouse.

\section{Population and Sampling}

Population: students enrolled in Computer Applications Course, College of Education, Imam Abdul Rahman bin Faisal University. 
Table 1. The experimental design of variables

\begin{tabular}{llll}
\hline Item & Pre-application & Treatment & Post-application \\
\hline Experimental group & Pre-information test & Web 2.0-based e-book & $\begin{array}{c}\text { Cognitive performance test. } \\
\text { Skill performance observation card. }\end{array}$ \\
\hline Control group & &
\end{tabular}

Sampling: the sample consisted of (60) students enrolled in Computer Applications course in 2016/2017, College of Education at the University of Imam Abdul Rahman bin Faisal. The participants were divided into two groups: the control group (25) and the experimental group (25), as well as (10) students for pilot study. Imam Abdulrahman Bin Faisal University opened established in 1975, Dammam, Saudi Arabia. It opened with two pioneering colleges, the College of Medicine and the College of Architecture. Almost four decades later this academic institution has grown into a leading research university with 21 colleges spread throughout the Eastern Province and a student population of over 45,000 . It continues to grow and develop, continually assessing and improving its curricula and expanding its academic capabilities in all disciplines, while at the same time engaging the public in addressing environmental and community challenges.

\section{Method}

The quasi-experimental approach utilized to measure the effectiveness of the proposed e-book in the development of designing and utilizing cloud data warehouses skills among students of Imam Abdul Rahman bin Faisal University. Two equal groups selected: The control group studied using the traditional method, and the experimental group studied using e-book based on Web 2.0. Skill performance observation card and cognitive performance test applied to the students of both groups in designing and utilizing cloud data warehouse pre- and post- teaching.

The experimental design adopted to address the problem of the present study in the formation of two groups: the control group and experimental group.

Pre-test applied to the students of the two groups, then Computer Applications Course taught to the students of the two groups as following:

- The control group: Consisted of (25) students who studied using the traditional method,

- The experimental group: Consisted of (25) students who studied using e-book based on Web 2.0.

Post-teaching, skill performance observation and cognitive performance test applied to the students of both groups. Addressing the problem of the research is indicated through the experimental design shown in Table 1.

\section{Limitations}

The scientific material is limited to the application of database using Microsoft Access studied by the students of University of Imam Abdul Rahman bin Faisal. Wikipedia and Facebook pages would be also used. For human and spatial limitations, the application of the research is limited to a sample of students of the University of Imam Abdul Rahman bin Faisal. Time limitations is the Academic year 2016 2017.

\section{Tools}

1. A questionnaire to identify the skills required to design and utilize data warehouse (prepared by the two researchers).

2. An electronic performance test (prepared by both researchers).

3. A skill performance observation card (prepared by both researchers).

\section{Terminology}

E-book: It is defined by Azmi and Al-Mradni (2010) as digital content available on the web consisting of a series of interactive, highly interactive pages, containing interesting multimedia elements and tools to interact with its content and structure. Mohammed (2008) sees it as a digital information medium produced by integrating the textual content of the book on one side and the applications of the digital environment on the other. According to Amin (2007), e-book is defined as "a technique for displaying printed or unprinted content in electronic form on the computer screen, depending on a variety of learning sources associated with the content; it can be browsed using desktop computers to provide the learner with the advantages of the electronic environment". It is also defined as a book or booklet in the form of electronic digital technology consisting of sequentially organized pages when connected to the network. It enables learners to communicate through the Web 2.0 applications and develop their cognitive and performance skills. 


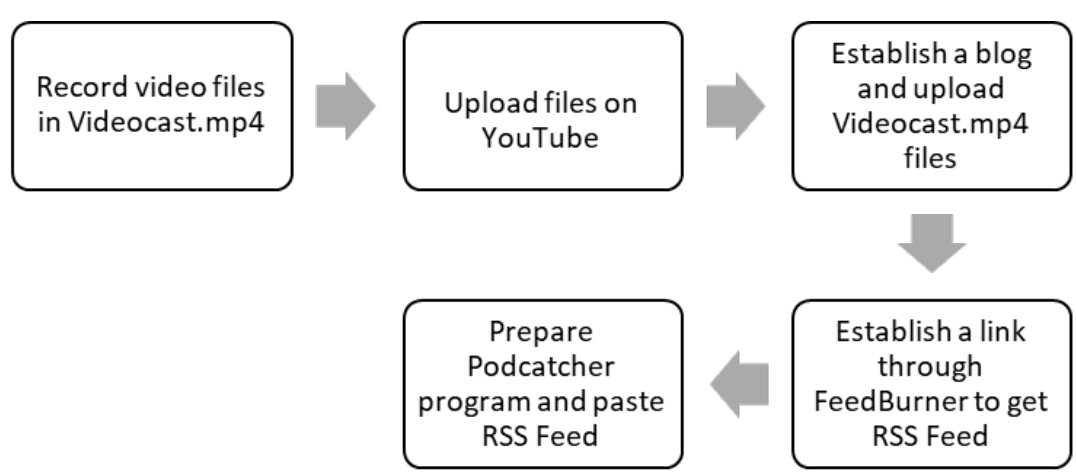

Figure 1. Steps of designing Video Casting tool

Web 2.0 Tools: Downes (2005) defines them as "the tools that enable learners to engage in an environment consisting of a network of people, services and resources." It is procedurally defined as: the tools that enable students to interact and communicate with their peers in terms of educational material and performance skills in order to improve their skilled performance. These tools are: Participatory Web Editors, Visual Blogging, Newsletters, and Social media.

Data Warehouses: Abdullah (2009) defines it as "a set of permanent historical data that help make administrative decisions," and contain huge amounts of data from different sources, or from several different data. It can be procedurally defined as a relational database designed to query and analyze to give better results in decision making. It is a type of database that contains a large amount of data intended to help the decision-making process within the organization.

\section{Procedures}

The study proceeds through two major steps: 1) preparing for the experiment by reviewing the previous studies pertaining to e-books, developing practical skills utilizing Web 2.0 technology and data warehouses as well as preparing experimental processing tools; 2) preparing the e-book. The educational design models related to the design of online educational programs reviewed in Al-Hadi (2005). The process of preparing the e-book conducted through five main stages, including analysis, design, production, implementation, and evaluation.

\section{Analysis}

The process of building the e-book begins with analysis including: a) analysis of learner characteristics, i.e. students of the College of Education who have previously studied Computer and able to use the Internet, e-mail, file download and chats; b) Analysis of Web 2.0 tools environment, three tools designed within the e-book environment, including Wiki, Video Casting and RSS. The Wiki tool is designed to provide students with a theoretical background about digital data warehouse, since students have no access to this information because there is no manual to guide them. The content of the tool includes the concept, objectives, principles, stages and modern strategies of teaching digital databases.

The Video Casting tool is designed to present a range of teaching skills (correct and wrong) to students in order to exchange views and establish new knowledge about teaching practices. It helps to achieve the required performance level during designing and utilizing digital data warehouse. The tool contains skill performance of students recorded by a digital camera. Because of skills multiplicity, the lecture is divided to sections recorded separately to be easily uploaded on the internet. The steps of designing the tool can be summarized in Figure $\mathbf{1}$.

The RSS tool is designed to link between Wiki and Video Casting tools to notify students and teachers about news, comments and video cast posts on the e-book environment. It contains news brief, i.e. title, description and date. RSS tool is added to the e-book environment, news reader software installed on the computer, RSS link is clicked and the page title is pasted in News Reader. For in class education, mini-teaching laboratory in the College of Education is equipped with (30) computers connected to the Internet, whiteboard and data show. For outside class education (at home), learning happens through the e-book where lectures prepared in the form of multimedia files (video - audio - pictures) and lecture repetition is available. The e-book aims to develop knowledge, skills and trends related to the design and use of data warehouses among students of the College of Education. For achieving the purpose of e-book, the content is set according to course description, books, references and scientific journals interested in this field. 


\section{Design}

Designing the e-book begins with organizing the e-book educational objectives by describing the learner behavior, the course and each educational unit in the form of statements. A flow map of the course developed for organizing and presenting the content. The course content organized in five modules, taking into account the logical sequence. A set of educational tasks and activities related to digital warehouse of each unit have been prepared, such as using search engines and websites to complete learning tasks such as photo collection, writing a report, etc., participating in panel discussions and communicate with colleagues through classroom discussions, sending and receiving emails and uploading files, generating images linked to cloud warehouse and presentations and presenting tasks through the forum of the e-book.

The e-book is presented through utilizing several strategies depending on integration between traditional classroom education and e-learning to achieve the objectives of the e-book. So, these strategies can be integrated according to the educational situation and the characteristics of the learners through the options provided by the e-book. It includes discussion, brainstorming, e-learning participation and e-learning projects. These strategies were chosen to allow students to express their views and encourage participation. For the design of teaching aids and learning resources, explanation depends on video and audio files and images contained in the e-book. Data projector and computers utilized in the computer lab to present activities, participatory tasks and answers of question bank. The e-book adopted many means, including pictures, drawings, recordings, video files, e-books and references and websites to teach science.

Interaction happens through student participation as available in the e-book, including synchronous or asynchronous interaction through e-mail. It takes place through the discussion of assignments and tasks in the lecture. Moreover, group learning mode utilized through a weekly lecture inside the class. Outside the lecture, individual learning mode based on e-book is adopted, allowing students and researchers to interact and talk about the design and use of digital Cloud Data Warehouse. Evaluation is conducted through three tools: 1) pre-evaluation through implementing pre-research tools and units pre-tests. 2) Formative evaluation through feedback during the study of the e-book and at the end of each unit. 3) Final evaluation through implementing post-research tools, student achievements in assignments and tasks and post-tests for each unit and the general test of the electronic book.

\section{Production}

The e-book has been submitted to a group of reviewers to state their reviews and evaluate its validity and they declared the validity of implementing the e-book. Accordingly, the e-book teaching plan has been developed as a guide for the student to help them understanding the order of the course. The plan includes the general objective of the course, the objectives of the educational unit, the topics it contains, the educational activities, the method of implementation and the schedule of studying the course.

\section{Implementation}

This phase begun with pilot experiment, to ensure that the e-book is free of spelling or technical errors or any design problems. It was tested on (10) students at the College of Education. The necessary amendment was made in the light of the results of the pilot experiment. Then, the proposed e-book is implemented and post-research tools applied.

\section{Evaluation}

Evaluation of student learning of the course and measuring its effectiveness depending on student performances during the e-book study, such as participation, interaction, the use of e-mail, participation in the chat room and expressing opinion. In addition to products represented in completing the required tasks such as the publication of pictures or video or audio recording and performing electronic tests for each educational unit. Final test performance of educational knowledge associated with the skills of designing digital data warehouse, note card of design and use skills and performance testing.

To identify the cognitive skills required to design and utilize data warehouse and to be developed among students of the College of Education at Imam Abdul Rahman bin Faisal University, the pieces of literature related to the criteria of designing and utilizing data warehouse, reviewed. The skill list, in its initial form, submitted to reviewers specialized in education technology and techniques. According to their opinions, a final list of skills is developed, as shown in Table 2. 
Table 2. Skills of designing and utilizing data warehouses

\begin{tabular}{lcc}
\hline Skills of designing and utilizing data warehouse & Sub-Skills & Relative weight \\
\hline Designing and utilizing tables in the database & 4 & $11 \%$ \\
\hline Designing a database by Microsoft Access software & 4 & $37 \%$ \\
\hline Linking between tables in the database & 4 & $18.5 \%$ \\
\hline Designing and utilizing queries & 4 & $7.5 \%$ \\
\hline Designing and utilizing models & 4 & $13 \%$ \\
\hline Designing and utilizing reports & 4 & $13 \%$ \\
\hline Total & 24 & $100 \%$ \\
\hline
\end{tabular}

Table 3. Agreement percentage on observation card indicators

\begin{tabular}{cccccccccccc}
\hline student & $\mathbf{1}$ & $\mathbf{2}$ & $\mathbf{3}$ & $\mathbf{4}$ & $\mathbf{5}$ & $\mathbf{6}$ & $\mathbf{7}$ & $\mathbf{8}$ & $\mathbf{9}$ & $\mathbf{1 0}$ & Reliability mean \\
\hline Agreement rate & $84.5 \%$ & $82.2 \%$ & $88.7 \%$ & $84.6 \%$ & $80.6 \%$ & $83.1 \%$ & $88.3 \%$ & $87.9 \%$ & $82.5 \%$ & $86.7 \%$ & $84.9 \%$ \\
\hline
\end{tabular}

Table 2 shows that the skill of 'Designing a database by Microsoft Access software' obtained the first rank of importance followed by the skill of 'linking between tables in the database' which got the second rank. The skills of 'designing and utilizing models' and 'designing and utilizing reports' had the same relative weight. Finally, the skill of 'designing and utilizing queries' obtained the lowest relative weight.

\section{Tool Validity and Consistency}

The initial form of the questionnaire submitted to a set of examiners to check its validity in terms of items comprehensiveness and appropriateness to identify the skills required for designing and utilizing data warehouse in Computer Course. The author met the examiners during and after checking the questionnaire to discuss any questions that may be raised and their views concerning:

- Appropriateness of the item for measuring the targeted skill.

- Validity of items phrasing.

- Clarity of the questionnaire instructions.

- Adding or deleting any items.

The examiners agreed on the comprehensiveness and appropriateness of the questionnaire to identify the skills required for designing and utilizing data warehouse in Computer Course.

Consistency of the questionnaire items calculated by the correlation coefficient between each score of the questionnaire item and the total score of the questionnaire items for the scores of the pilot sample students. Correlation coefficients obtained in the closed period [0.53- 0.95]. Consequently, correlation coefficients were statistically significant at 0.01 indicating the consistency of the questionnaire items.

The skill performance observation card designed to measure the sample performance level of designing and utilizing data warehousing skills. Observation card paragraphs edited in the form of specific and clear procedural phrases, as each phrase describes one performance pattern. The observation card includes the same dimensions of designing and utilizing data warehouse skills of the sample, Table 1 where the total number of sub-skills is (24). The observation card instructions edited in precise and clear form clarifying its objective, nature and how to record the observation. For observation card reliability, it submitted to reviewers and the necessary amendments conducted according to their views and suggestions. Observers agreement method utilized to calculate the observation card reliability. With a staff member at the College of Education, the card applied to a sample of (10) students enrolled in the College of Education for the academic year 2016/2017. The agreement rate calculated through Cooper equation:

$$
\text { Agreement rate }=\frac{\text { agreed times }}{\text { agreed times }+ \text { disagreed times }} \times 100
$$

Table 3 shows agreement percentage.

Cooper identified consistency level in terms of agreement percentage, as follows: Less than (70\%) low card consistency and $(85 \%)$ high card consistency. Table 2 shows that the mean agreement rate is $(84.9 \%)$, denoting high consistency of the card utilized to measure the level of student performance (Khtab, 2000). Four cells allocated for each sub-skill to represent the quantified performance score as follows: (3) scores for high skill performance, 2 scores for intermediate performance, one degree for lower performance and zero if the skill is not performed. The highest score for each card is (72), intermediate score (36) and (24) the lowest score. 
Table 4. Test specifications for the skills of designing and utilizing data warehouses

\begin{tabular}{|c|c|c|c|c|c|c|c|c|}
\hline Learning levels dimensions & s Remembering & Understanding & Analyzing & Applying & Evaluating & Creating & Total & $\begin{array}{c}\text { Relative } \\
\text { weight }\end{array}$ \\
\hline $\begin{array}{l}\text { Databases concepts and } \\
\text { terminology }\end{array}$ & 2 & 2 & - & 2 & - & 1 & 7 & $20.8 \%$ \\
\hline Cloud databases & 1 & - & - & 2 & 1 & - & 4 & $29.2 \%$ \\
\hline $\begin{array}{l}\text { Data warehouse } \\
\text { management }\end{array}$ & - & 1 & - & 2 & - & - & 3 & $25 \%$ \\
\hline $\begin{array}{l}\text { Data warehouse design } \\
\text { technology }\end{array}$ & - & 2 & - & - & 1 & 1 & 4 & $12.5 \%$ \\
\hline $\begin{array}{l}\text { Databases warehouses } \\
\text { use evaluation }\end{array}$ & 1 & - & 1 & - & - & - & 2 & $12.5 \%$ \\
\hline Total & 4 & 5 & 1 & 6 & 2 & 2 & 20 & $100 \%$ \\
\hline Relative weight & $16.7 \%$ & $18.7 \%$ & $18.7 \%$ & $16.7 \%$ & $12.5 \%$ & $16.7 \%$ & $100 \%$ & \\
\hline
\end{tabular}

\section{Cognitive Performance E-Test}

Cognitive performance e-test designed to measure the cognitive skills of the sample pertaining to the skills of designing and utilizing data warehouse. The dimensions of the test represent the units contained in the databases course for the sample. The test items composed of multiple choice pattern including (20) items distributed to measure different cognitive levels. Correct answer choice phrases not less than four including one correct answer. According to behavioral goals, items have diverse levels and comply with the test specifications of Bloom Taxonomy.

Table 4 shows that the learning dimension of 'Cloud databases' obtained the first rank of importance followed by 'Data warehouse management' which got the second rank. While 'databases concepts and terminology' had the third rank, 'data warehouse design technology' and 'databases warehouses use evaluation' obtained the lowest relative weight. It also indicates that the relative weight percentage for 'understanding' and 'analysis' of the learning dimensions obtained the first rank, followed by 'remembering' and 'applying' which obtained the second rank. It helps determine the number and specifications of questions related to each learning level dimension in the test.

Test instructions are clear, answer sheet as well as test correction key prepared. The test submitted to reviewers to ensure its scientific and linguistic validity as well as suitability to the measured level of knowledge. The test items modified and the final test includes (20) items. Pilot study for the test conducted to a sample consisted of 10 students enrolled in the College of Education in the academic year 2016/2017, to calculate:

1. Test consistency coefficient using Cronbach equation and applying the test one time, it equals (.76).

2. Test time by the following equation:

$$
\text { Test time }=\frac{\text { time taken by the first student }+ \text { time taken by the last student }}{2}
$$

By applying the equation, the test time is (30 minutes), acceptable time to perform the test.

3. Simple and distinguished items coefficient (Al-Bahi, 1978), where items obtained suitable simple and distinguished coefficient.

4. Ensure clarity of the test instructions, which were clear to the students and written in an easy accurate language. So that, the test has a high level of validity and reliability to be applied.

Test score identified by giving one point for choosing the correct answer and zero for choosing the wrong answer, and thus, the highest score of the test is (20). The final form of the test applied as it became on the appropriate level of reliability and consistency. SPSS software utilized to schedule and process the results of the application of the program.

\section{RESULTS AND DISCUSSION}

The cognitive skill results for experimental and control groups are compared to verify the validity of the first hypothesis, stating that There was a significant difference between the mean scores of student in the cognitive test of the experimental and control groups, in favor of the experimental group due to the impact of e-book based on Web 2.0 on developing the skills of utilizing data warehouse in post-measurement. The experimental group students exposed to the e-book based on Web 2.0 compared to control group students exposed to the traditional training program, with regard to the cognitive skills of designing and utilizing Cloud Data Warehouse. 
Table 5. Experimental and control groups means, standard deviations and T-test

\begin{tabular}{|c|c|c|c|c|c|c|c|}
\hline Group & Application & No. & Mean & $\begin{array}{l}\text { Standard } \\
\text { deviation }\end{array}$ & $\begin{array}{c}\text { Freedom } \\
\text { degree }\end{array}$ & $\mathbf{T}$ value & $\begin{array}{c}\text { Significance } \\
\text { Level }\end{array}$ \\
\hline \multirow{2}{*}{ Control } & Pre- application & \multirow{4}{*}{25} & 18. 11 & 4.05 & \multirow{4}{*}{50} & \multirow{4}{*}{9.98} & \multirow{4}{*}{$\leq 0.05$} \\
\hline & Post- application & & 25.39 & 5. 90 & & & \\
\hline \multirow{2}{*}{ Experimental } & Pre- application & & 28.43 & 4.32 & & & \\
\hline & Remote application & & $36: 25$ & 3.45 & & & \\
\hline
\end{tabular}

Table 6. Means, standard deviations and T significance in pre- and post-application

\begin{tabular}{|c|c|c|c|c|c|c|c|}
\hline Group & Application & No. & Mean & $\begin{array}{l}\text { Standard } \\
\text { Deviation }\end{array}$ & $\begin{array}{c}\text { Freedom } \\
\text { Degree }\end{array}$ & T value & $\begin{array}{c}\text { Significance } \\
\text { level }\end{array}$ \\
\hline \multirow{2}{*}{ Control } & Pre-application & 36 & 8.43 & 2.72 & \multirow{2}{*}{24} & \multirow{2}{*}{42.08} & \multirow{2}{*}{$\leq 0.05$} \\
\hline & Post-application & 36 & 23.61 & 3.45 & & & \\
\hline \multirow{2}{*}{ Experimental } & Pre-application & 36 & 10.14 & $1: 46$ & \multirow{2}{*}{24} & \multirow{2}{*}{47.00} & \multirow{2}{*}{$\leq 0.05$} \\
\hline & Post-application & 36 & 36.25 & 2. 32 & & & \\
\hline
\end{tabular}

T-Test for two independent samples utilized to identify the differences between the cognitive performance level for the control and the experimental groups students in post-application of the cognitive test in the performative side.

Table 5 shows that there were significant differences at the level (0.05) between the mean scores of experimental group students exposed to the e-book based on Web 2.0 compared to control group students exposed to the traditional training program, for the experimental group. Accordingly, the first hypothesis accepted, which means that there is a significant difference between the mean scores of student in the cognitive test of the experimental and control groups, in favor of the experimental group due to the impact of e-book based on Web 2.0 on developing the skills of utilizing data warehouse in post-measurement.

\section{The E-Book Impact Size on Performance}

The impact size can be defined as a quantitative value indicating the relationship degree between study variables within a pre-defined population, regardless of the statistical method utilized to express that impact. It means to express the relationship between the independent and dependent variables by obtaining the size of the dependent variable variation which can be explained by the independent variable. The value of the impact size utilizing Eta-Squared of the cognitive skill is (0.168), a big and appropriate value exceeding the significant value of educational signification (15.0) for the statistical results in educational, psychological research. Accordingly, the ebook based on Web 2.0 has a significant educational impact on the experimental group students.

T-Test for paired samples utilized to verify the second hypothesis, stating that there is a significant difference between the mean scores of students in the skill performance observation card of the experimental and control groups in favor of the experimental group due to the impact of e-book based on Web 2.0 on developing the skills of utilizing data warehouse in post-measurement.

Table 6 shows that there were significant difference at the level (0.05) between the mean scores of the control group students who utilized traditional Cloud Data Warehouses and the experimental group students in pre- and post-application of observation card of e-book Cloud Data Warehouses, for post-application. Accordingly, the second hypothesis is accepted. Black modified gain ratio utilized to measure the effectiveness of the integrated program of cognitive achievement to compare pre- and post-test mean of the experimental group, according to the following equation:

$$
\text { Black Modified Gain Ratio }=\frac{Y-X}{S-X}+\frac{Y-X}{S}
$$

where; $\mathrm{Y}$ is the mean scores of post-application, $\mathrm{X}$ the mean scores of pre-application and $\mathrm{S}$ the test final score.

Table 7 shows that the impact of the e - book based on Web 2.0 is acceptable for the experimental group, where Black modified gain ratio (1.36), i.e. < (1.2) the effectiveness identified by Black. It confirms the effectiveness of the e-book on the skill of designing and utilizing Cloud Data Warehouse. For cognitive skills of designing and utilizing Cloud Data Warehouse, the experimental group students exposed to e-book in designing and utilizing Cloud Data Warehouses are better than the control group students exposed to the traditional training program. For performative skills of designing and utilizing Cloud Data Warehouse, the results indicate to the effectiveness of the experimental group. 
Table 7. E-book impact on skills utilizing Black modified gain ratio

\begin{tabular}{ccccc}
\hline Group & $\begin{array}{c}\text { pre-application mean } \\
\text { score }\end{array}$ & $\begin{array}{c}\text { Post-application mean } \\
\text { score }\end{array}$ & Modified gain ratio & Significance Level \\
\hline Experimental & 10.14 & 36.25 & 1.36 & $\leq 1.2$ \\
\hline
\end{tabular}

\section{CONCLUSION}

The e-book based on Web 2.0 in designing and utilizing Cloud Data Warehouses provides many advantages, such as improving the effectiveness and efficiency of training, flexibility and availability of multiple channels, combining the advantages of e-learning and traditional training. In addition, face-to-face communication increases student interaction as well as student-teacher interaction and student-content interaction through workshops and training on activities related to utilizing Cloud Data Warehouses and communication tools, such as e-mail and Facebook. Through the implementation of individual and collaborative activities, trainees are able to interact and be trained on multiple activities achieving a positive impact on their understanding through Web 2.0 participatory and interactive applications. Moreover, learning by e-book based on Web 2.0 contributed to solving the problem providing paper copies of the educational materials and presentations. In addition, ebook based on Web 2.0 attracts student attention for a longer period through appropriate various activities, interactive communication between the student and the e-book and providing students with the appropriate feedback as emphasized by the visual communication theory.

Cloud Data Warehouses, including workshops and training site contains presentations, training material, stable images and video clips that link between the student's memory and the presented material and attract his attention to the curriculum details. Thus, the training becomes more effective and applicable as indicated by Stimuli Summation Theory. Thus, e-book based on Web 2.0 in designing and utilizing Cloud Data Warehouse provides interactive multi - modal learning that includes more interaction with content, student and teacher through online communication tools provided by Web 2.0. These advantages are not available in traditional education carried out in the framework of specific learning hours.

\section{RECOMMENDATIONS}

In the light of the research results, it is recommended to make use of the proposed principles and standards in the field of education through providing them to the planners of special educational Web 2.0 programs in public and university education. The proposed e-book based on other tools of Web 2.0 can be applied on other courses of pre-university and university education. It is important to provide a theoretical manual for training on utilizing Cloud Data Warehouse containing a theoretical background to help students performing digital computing practices. Adopting a unified Arab project in order to provide e-schoolbooks which include theoretical questions, images, video and slide show training programs. Attempt to characterize and prepare a curriculum contains educational and technological foundations of the e-book based on Web 2.0 depending on utilizing technology in education.

\section{SUGGESTIONS FOR FURTHER STUDIES}

1. Applying e-learning within a traditional learning environment, i.e. not to demolish traditional learning, but utilizing both of them in a complementary manner, especially for young children education.

2. An Analytical study on Internet networks rehabilitation and providing the possible electronic means for schools and educational institutions.

3. A Study on e-learning in university work, especially for graduates focusing on their graduation projects.

4. Building a digital system specialized in e-learning for elementary stage as a first stage of application. The idea is to provide e-learning system equivalent to the subject given in elementary stages, enhanced by examples, explanations and realistic simulation based on full documentation (video, flash, audio files and examples) to be a permanent reference.

\section{REFERENCES}

Abdullah, H. (2008). The impact of using web2 on the collaboration learning skills. Education College of Umm Alqura University.

Abdullah, A. (2009). Data Warehouse. Retrieved on 27/1/2018 from https://goo.gl/3un3SY 
Abu Shawish, A. A. (2013). Proposal for the development of the skills of designing e-courses for technology education students (MA Thesis). Al-Aqsa University, Gaza, College of Education, Islamic University of Palestine. Retrieved from http:/ / library.iugaza.edu.ps/thesis.aspx

Al-Bahi, F. (1978). Statistical psychology and human mind measurement. Egypt, Cairo: Dar El-Fkr Al-Arabi.

Al-Dahsh, A. M. (2007). E-learning: ongoing development, training and techniques. General Organization for Technical Education and Vocational Training, (96), Riyadh.

Al-Far, I., \& Shahin, S. (2001). Electronic school: A new vision for a new generation. Eighth Scientific Conference of the Egyptian Society for Educational Technology, Electronic School, Girls College, Ain Shams University, p. 38-49.

Al-Garf, S. R. (2008). Requirements of electronic curricula model activation in Saudi public education. E-Learning first forum. Saudi Arabia, Ministry of Education. Retrieved from http://www.eqra.com.sa/Data/dt0021.pdf

Al-Hadi, M. M. (2001). Communication technology and information network. Cairo: Academic Library.

Al-Hadi, M. M. (2005). E-Learning. Cairo: Egyptian Lebanese House.

Al-Hoseiny, A. M. (2005). The use of e-book in university education and its impact on acquiring the skill of computer maintenance (Unpublished MA thesis), Department of Educational Technology, College of Education, Ain Shams University.

Al-Naeimi, N. M. (2001). The impact of multimedia software with internet access on the level of information among students with external and internal control sources and their achievement in the field of educational technology. E-School, the $8^{\text {th }}$ scientific conference of the Egyptian assembly for Education Technology, the Faculty of Girls, Ain Shams University, 2001. Cairo: Alam Al-Kutb, 279-314.

Amin, M. Z. (2007). E-Book and its impact on educational achievement for technology students with high and low self-management of knowledge. College of Education Journal, University of Beni-Suef, p. 9.

Artman, E. M. (2003). Motivation factors to overcome faculty resistance to integrating asynchronous online education in higher education business courses (Doctoral Dissertation). San Francisco, CA: University of San Francisco.

Ateya, M. (2003). Products of education technology. Cairo: Dar Al Kalima.

Azmi, G. N. (2008). E-Learning Technology (First Ed.). Dar Al-Fikr Al-Arabi, Cairo. p. 85.

Azmi, G. N., \& Al-Mradni, M. M. (2010). The impact of interaction between various patterns of learning structural pillars within e-book in achievement and efficiency among graduate students at girls colleges. College of Education Journal, 16(3), p. 260. Helwan University.

Batoush, K. (2002). E-Publishing and the inevitability of access to information at the Algerian University Library. Journal of Libraries and Information, $1(1)$.

Downes, S. (2005). E-learning 2.0. Retrieved on March 3, 2007 from http:/ / www.downes.ca/post/31741

Downes, S. (2006). E-learning 2.0, elearn MAGZINE Association of Computing Machinery. Retrieved on Jan, 3, 2008 from http:/ / www.elearnamag.org

El-Khoury, Sh. H. (2000). E-publishing and the future of the printed word. Arab Journal.

Gardner, J. (2008). The Reliability of assessments and learning (Second Ed.). Sage Chapter in Book/Report/Conference proceeding > Chapter, p. 243-263.

Gewertz, C. (2012). Test Designers Tap Students for Feedback. ERIC Document reproduction Service No. (EJ1000124).

Hassan, Y. A. (2008). The impact of utilizing E-Learning 2.0 on cooperative education skills among students of Teachers College in Abha (PhD Thesis). College of Education, University of Umm Al- Qura.

Ismail, R. (2013). The impact of utilizing e-book in developing the skills of dealing with the computer and motivation for achievement of students in the third grade independent and accredited preparatory schools (Unpublished MA), College of Education, Department of Teaching Curriculum and Methods, Minia University.

Ismail, Z. A.-G. (2009). Electronic courses: design, production, dissemination, implementation and evaluation. Egypt, Cairo: Alam El-Kutb.

Khtab, M. A. (2000). Measurement and Evaluation in psychological, educational and social sciences (2nd Ed.). Egypt, Cairo: Anglo-Egyptian library.

Livingstone, S., \& Bulger, M. C. (2015) A global research agenda for children's rights in the digital age. Journal of Children and Media. https:/ / doi.org/10.1080/17482798.2014.961496

Mabrouk, I. M. (2011). The impact of content presentation strategies in the integrated learning environment on developing the skills of developing e-learning resources and their use among students (Unpublished PhD thesis), Department of Learning Technology, College of Education, Helwan University. 
Mahmoud, S. (2007). The impact of e-book design variables on achievement and self-learning skills and impressions of students in the technology curriculum (Unpublished MA thesis), Girls College, Ain Shams University.

Mazen, H. (2009). Information Technology and Electronic Media. p. 80, Egypt: Sohag.

Milman, D. (1999). Strategies for the design and delivery of blended learning courses. Educational Technology, 46(6).

Mohamed, R. E. (2005). The impact of a program based on integrated e-learning on the skills of designing the individual educational plan for special education teachers (Unpublished PhD thesis), Faculty of Kindergarten, Alexandria University.

Ramal, M. (2009). The role of database modern technology in constructing information society in the Arab World. Retrieved on 11/2/2018 from https:/ / goo.gl/94Kodi

Remal, M. (2009). The role of technologies to build Arabic information society. Retrieved from http:/ /www.arabcin.net/arabic/5nadweh/pivot_3/new_technique.htm

Reynolds, D. (2002). Preparation of mathematics teachers: Lessons from review of literature on teachers' knowledge beliefs and teacher. Education Journal of classroom interaction 2, 3-15.

Rowhani, S., \& Sedig, S. (2005). E-book plus role of interactive informative visuals in exploration. Journal of Computer in Mathematics and Science Teaching.

Sadeq, M. U. (2001). The E-book. The 12th Arab Conference of the Arab Federation of Libraries and Information, entitled: Arab Libraries at the Beginning of the Third Millennium, Sharjah, 5 - 8 November 2001.

Shimi, S. A. N. (2013). Innovative concepts and visions to develop interactive e-content in Egypt. Third Conference of e-learning and distance education. Saudi Arabia, Riyadh, p. 1-23. Retrieved from http:/ / eli.elc.edu.sa/2013 /

Shiratuddin, L., Gibb, F. M., \& Hassan, Sh. (2002). E-Book technology and its potential applications in distance education computer and information sciences Department. University of Strath clyde, 26 Richmond Street.

Sorour, A. S. (2003). Management of modern databases. p. 54. Riyadh: Dar Al-Mareekh for Publishing and Distribution.

\section{http://www.ejmste.com}

